\title{
Appropriate Titration of Basal Insulin in Type 2 Diabetes and the Potential Role of the Pharmacist
}

Dhiren Patel $\cdot$ Curtis Triplitt $\cdot$ Jennifer Trujillo

Received: October 18, 2018 / Published online: March 21, 2019

(C) The Author(s) 2019

\section{ABSTRACT}

A substantial proportion of patients with suboptimal control of their type 2 diabetes experience delays in treatment intensification. Additionally, patients often experience overuse of basal insulin, commonly referred to as "overbasalization," whereby basal insulin continues to be uptitrated in order to meet targets, when addition of a mealtime bolus insulin dose may be a more appropriate option. In order to overcome these challenges, there is a need to develop the capacity of allied healthcare professionals to provide appropriate support to these patients, such as during initiation or titration of basal insulin. Pharmacists play an integral role in healthcare delivery, with

Enhanced Digital Features To view enhanced digital features for this article go to https://doi.org/10.6084/ m9.figshare.7701077.

D. Patel $(\bowtie)$

School of Pharmacy, MCPHS University, Boston, MA, USA

e-mail: dhiren.patel1@mcphs.edu

C. Triplitt

Texas Diabetes Institute, University of Texas Health

Science Center, San Antonio, TX, USA

J. Trujillo

Skaggs School of Pharmacy and Pharmaceutical

Sciences, University of Colorado, Aurora, CO, USA patients seeing their pharmacist, on average, seven times more often than their primary care physician. This places pharmacists in a unique position to provide diabetes education and care, which may help patients avoid clinical inertia. Nevertheless, the management of the disease with basal insulin is becoming increasingly complex, with growing numbers of treatment options (such as recent second-generation longer-acting basal insulin formulations) and frequently updated titration algorithms. The two most common titration schedules specify either increasing doses by a set amount every 2-3 days or a treat-to-target strategy. Neither schedule has been shown to be superior, and the decision to use one or the other should be based on a discussion between the clinician and patient after assessment of mental and physical acumen, comfort of both parties, and follow-up plans. This review article discusses basal insulin therapy options and titration algorithms from the unique perspective of the pharmacist in order to help ensure that optimal antidiabetes therapy is initiated, appropriately titrated, and maintained.

Funding: Sanofi US, Inc.

Keywords: Basal insulin; Basal insulin overuse; Pharmacist; Titration algorithm; Type 2 diabetes 


\section{INTRODUCTION}

It has been estimated that around 422 million adults worldwide were living with diabetes in 2014 , representing an increase in prevalence of $3.8 \%$ from 1980 in the adult population [1]. The majority of these cases represent type 2 diabetes (T2D) and reflect the increased prevalence of risk factors, which include an aging population, the current obesity epidemic, and lifestyle factors such as an unhealthy diet, physical inactivity, and smoking [1]. Patients with T2D have an increased risk of cardiovascular and cerebrovascular morbidity and mortality, as well as other diabetes-associated complications such as visual impairment, renal failure, and lower-limb amputations. Achieving and maintaining glycemic control reduces the long-term risk of microvascular complications [2]; however, despite the availability of detailed management guidelines [2-6] and a wide range of treatment options, almost half of patients with diabetes in the USA fail to achieve adequate glycemic control, defined by a glycated hemoglobin A1c (HbA1c) level < 7\% [7].

Protracted failure to achieve glycemic targets as a result of delayed insulin initiation puts patients at risk of diabetes-associated complications and premature death [8]. Among patients who fail to meet glycemic goals, a substantial proportion experience clinical inertia (a delay in treatment intensification despite suboptimal glycemic control). Clinical inertia is not only a problem among patients who are yet to initiate injectable therapy but also for those who require further intensification following commencement of injectable therapy, with median times to initiate and intensify insulin therapy of several years $[9,10]$.

Clinical inertia is multifactorial, with contributory factors from patients and clinicians. These include fear of hypoglycemia [11], concerns regarding weight gain, and the perceived complexity of insulin regimens, which impact patients' day-to-day lives and clinicians' resources, leading to poor adherence [11]. From the patient's perspective, injectable therapy is associated with the belief that their diabetes is worsening [12]. In addition, physicians may lack the support, knowledge, and training necessary to optimally manage T2D, for which there has been a rapid increase in treatment options within a relatively short period of time, alongside changes in the recommended approach to patient management. For example, the emphasis on individualization of treatment goals and therapy choice in treatment guidelines could paradoxically encourage clinical inertia because no clear recommendations as to how to achieve this personalization are given [8].

Today, the majority of patients with T2D are managed in primary care settings. However, as the incidence of T2D increases, it is likely that physicians will have less time to manage patients in an optimal manner [13]. Therefore, there is a need to encourage the involvement of other healthcare professionals in patient-facing roles across all settings, who may be in a unique position to provide support in the management of these patients, either as independent practitioners or as part of a multidisciplinary team. This may help ensure optimal therapy is initiated and maintained in a timely manner for individual patients. In this narrative review, we outline the important role that pharmacists can play in diabetes care, briefly summarize the main advantages and disadvantages of the different types of basal insulins, and provide information on titration, with a focus on the newer longer-acting basal insulins. This article is based on previously conducted studies and does not contain any studies with human participants or animals performed by any of the authors.

\section{ROLE OF THE PHARMACIST IN DIABETES CARE}

Pharmacists play an integral role in the healthcare delivery system in the USA and are one of the most accessible healthcare professionals in most communities [14]. A meta-analysis comparing prescribing practices for the management of acute and chronic health conditions in primary and secondary care found that nonphysician prescribers (e.g., nurse practitioners, pharmacists, and physician assistants) were as effective as physician prescribers, delivering 
comparable outcomes across a range of indices, including HbA1c control, medication adherence, patient satisfaction, and health-related quality of life [15]. Moreover, patients with diabetes see their pharmacists on average seven times more often than they see their primary care physician [14], placing patient-facing pharmacists in a unique position to provide education and care.

The beneficial impact of pharmacists' involvement specifically in the management of diabetes was demonstrated in a meta-analysis of 14 studies comprising 2073 patients, which showed statistically and clinically significant associations between pharmacist intervention and improvements in both $\mathrm{HbA} 1 \mathrm{c}$ and fasting plasma glucose (FPG) [16]. A retrospective chart review revealed that referral to a medication-therapy management and education service provided by clinical pharmacists resulted in a statistically significant reduction in HbA1c and an increase in the number of patients achieving HbA1c < 7\% [17]. Pharmacist-managed diabetes care services can also improve screening rates and achievement of glycemic and lipid goals [18]. In a randomized controlled trial, pharmacist intervention led to significant improvements in HbA1c and was particularly beneficial when patients switched the type and/ or dose of antihyperglycemic agents [19].

Pharmacists' roles are increasingly moving beyond the more traditional aspects of screening, education, and monitoring. Within the Veterans Health Administration, clinical pharmacist specialists (CPSs) have independent prescriptive authority to provide comprehensive medication management for patients with chronic diseases, including diabetes, and play an active role not only in prescribing antihyperglycemic agents but also in addressing adverse events such as hypoglycemia [20]. CPSled therapeutic monitoring clinics can have a significant beneficial impact on glycemic control for patients living in rural areas with limited access to medical facilities. A retrospective chart review found that veterans with HbA1c $\geq 8 \%$ who were referred to a CPS-managed clinic and persisted with their visits showed significant HbA1c reductions, with $74 \%$ achieving HbA1c $<8 \%$. The veterans also showed significant improvements in diastolic blood pressure, total cholesterol, and triglyceride levels [21]. In a rural area, remote intervention using a real-time, clinic-based video program led by a CPS also resulted in a significant decrease in $\mathrm{HbA1c}$ and in an increased number of veterans achieving glycemic goals after 6 months, with patients reporting a high level of satisfaction with the service [22]. Finally, a recent meta-analysis of 11 studies evaluating the effects of community pharmaceutical care and therapy management services for patients with diabetes further showed, in addition to improvements in glycemic control, the effectiveness of a wide range of patientcentered and interdisciplinary interventions led by pharmacists, which included providing feedback to clinicians, defining individualized glycemic targets, and checking the patients' level of knowledge of their treatment regimens [23]. The practice setting in this specific metaanalysis is of particular relevance because most of the studies assessed the role of clinical/hospital pharmacists as opposed to community pharmacists [16], although the sample size was relatively small [23]. It should be noted that two out of six studies in the community setting for which HbA1c data were available included patients on insulin therapy [23].

Perhaps one of the most important periods when a patient with diabetes requires support is during the initiation and titration of basal insulin. A retrospective cohort study in the USA showed that, compared with physician management alone, a pharmacist-managed insulintitration program resulted in significantly greater HbA1c reductions, with a greater proportion of patients adhering to recommended preventive care measures [24]. Although guidelines state that most patients can be taught to titrate their own insulin dose using simple algorithms, they also point out that frequent contact may be necessary during this period [2]. The findings of the aforementioned study show that pharmacists are well placed to offer support, for example, helping to ensure that patients understand their medication and titration schedule and checking for hypoglycemia. In addition, a study assessing the impact of pharmacist-led face-to-face initiation 
and titration of basal insulin in a Veterans Affairs Health Care System, using a pre-planned protocol, resulted in improvement in patient glycemic control [25]. Similarly, a study of community pharmacies in Canada showed that independent prescribing, initiation, and titration of insulin by pharmacists resulted in an HbA1c reduction from $9.1 \%$ to $7.3 \%$ over 26 weeks [26]. Other studies on pharmacist-led titration services in the USA showed similar positive impacts on glycemic control; significant improvements in HbA1c were seen with pharmacist-managed insulin titration compared with standard care in underserved patients with T2D [27] and with titration-byphone as part of the pharmacy services in a family medicine department [28].

An adequate insulin dosing process is thus essential for optimal clinical outcomes. If patients do not receive support during titration they may skip doses or stop taking insulin altogether. Pharmacists can develop protocols for more frequent follow-ups to ensure better titration. In addition, they can ensure that insulin titration is proceeding according to the guidelines in a safe, effective, and evidencebased manner (i.e., asking patients about their glycemic goals whenever they refill a prescription and if they are taking the adequate doses, making sure they understand the dose titration schedule, inquiring about their injection techniques and blood glucose measurement practices, and asking about hypoglycemia) [29].

Therefore, pharmacists need to be well versed in the types of insulin available and their pros and cons, as well as the guidelines and process of basal insulin initiation and titration and the potential issues that may arise, complementing the role of healthcare providers in the control of hyperglycemia and the monitoring of insulin therapy.

\section{INSULIN FORMULATIONS IN THE MANAGEMENT OF T2D}

T2D is a progressive disease; as $\beta$-cell function declines, escalation of treatment with oral antidiabetes drugs (OADs) becomes less effective, and ultimately insulin therapy becomes a major means of controlling hyperglycemia. Treatment guidelines recommend starting insulin treatment with basal insulin, usually in combination with metformin $[4,5]$, supporting the initiation of insulin at multiple junctures of the treatment algorithm in patients with HbA1c $\geq 9 \%$, in dual- and triple-therapy regimens, and as a combination with non-insulin injectable agents $[5,6]$.

In the USA, practitioners have a number of different options: intermediate-acting neutral protamine Hagedorn (NPH) insulin, long-acting basal insulin analogs (insulin glargine $100 \mathrm{U} / \mathrm{mL}$ [Gla-100] and insulin detemir [IDet]), and second-generation basal insulin analogs (insulin glargine $300 \mathrm{U} / \mathrm{mL}$ [Gla-300], insulin degludec $100 \mathrm{U} / \mathrm{mL}$ [IDeg-100], and insulin degludec $200 \mathrm{U} / \mathrm{mL}$ [IDeg-200]). There are also fixed-ratio combinations of basal insulins and glucagon-like peptide-1 receptor agonists available; however, our current discussion focuses solely on basal insulins. Information on the available basal insulins is presented in Table 1.

\section{NPH Insulin}

Intermediate-acting NPH insulin shows a pronounced peak effect, which is associated with a high degree of inter- and intra-patient variability and can complicate dose titration and lead to nocturnal hypoglycemia. Moreover, its duration of action is only $12-14 \mathrm{~h}$, which means that many patients will need twice-daily dosing to achieve full 24-h insulin coverage [35]. Ideally, NPH should be given in the evening/at bedtime in order to improve FPG. Although FPG goals can be achieved in many patients using this approach, the risk of nocturnal hypoglycemia is higher, in part because of absorption variability. A further practical consideration that complicates the use of NPH is that its pen cartridges are in a two-phase solution, requiring adequate mixing to ensure complete resuspension prior to injection; inadequate resuspension of NPH is common and may impair glycemic control [36]. However, $\mathrm{NPH}$ has the advantage of lower costs compared with basal insulin analogs. 
Table 1 Summary of basal insulin product characteristics

\begin{tabular}{|c|c|c|c|c|c|c|c|}
\hline Product & $\begin{array}{l}\text { Onset } \\
\text { (h) }\end{array}$ & $\begin{array}{l}\text { Duration } \\
\text { (h) }\end{array}$ & $\begin{array}{l}\text { Dosage forms } \\
\text { and strengths }\end{array}$ & $\begin{array}{l}\text { Insulin } \\
\text { units per } \\
\text { vial/pen }\end{array}$ & $\begin{array}{l}\text { Maximum single- } \\
\text { injection dose } \\
\text { for pen devices } \\
\text { (U) }\end{array}$ & $\begin{array}{l}\text { Median } \\
\text { cost }[6]^{\mathrm{a}} \\
(\mathrm{USD})\end{array}$ & $\begin{array}{l}\text { Storage days } \\
\text { at room } \\
\text { temperature } \\
\text { (in use) }\end{array}$ \\
\hline \multirow{3}{*}{$\begin{array}{l}\text { Insulin glargine } \\
\qquad 100 \mathrm{U} / \mathrm{mL}[30]\end{array}$} & \multirow[t]{3}{*}{$2-4$} & \multirow[t]{3}{*}{24} & $3 \mathrm{~mL}$ cartridges & 300 & \multirow[t]{3}{*}{80} & \multirow[t]{3}{*}{298} & \multirow[t]{3}{*}{28} \\
\hline & & & $10 \mathrm{~mL}$ vials & 1000 & & & \\
\hline & & & $\begin{array}{l}3 \mathrm{~mL} \text { prefilled } \\
\text { pens }\end{array}$ & 300 & & & \\
\hline $\begin{array}{l}\text { Follow-on insulin } \\
\text { glargine } 100 \mathrm{U} / \\
\mathrm{mL}[31]\end{array}$ & NA & 24 & $\begin{array}{l}3 \mathrm{~mL} \text { prefilled } \\
\text { pens }\end{array}$ & 300 & 80 & 253 & 28 \\
\hline $\begin{array}{l}\text { Insulin glargine } \\
\quad 300 \mathrm{U} / \mathrm{mL} \text { [32] }\end{array}$ & 6 & 24 & $\begin{array}{l}1.5 \mathrm{~mL} \text { prefilled } \\
\text { pens }\end{array}$ & $450 / 900$ & $80 / 160$ & 298 & 42 \\
\hline $\begin{array}{l}\text { Insulin degludec } \\
100 \text { or } \\
200 \mathrm{U} / \mathrm{mL}[33]\end{array}$ & 1 & $>42$ & $\begin{array}{l}3 \mathrm{~mL} \text { prefilled } \\
\text { pens containing } \\
\text { either } 100 \text { or } \\
200 \mathrm{U} / \mathrm{mL}\end{array}$ & $300 / 600^{\mathrm{b}}$ & $80 / 160^{\mathrm{b}}$ & 355 & 56 \\
\hline $\begin{array}{l}\text { Insulin detemir } \\
\qquad 100 \mathrm{U} / \mathrm{mL} \text { [34] }\end{array}$ & $\begin{array}{l}0.8-2 \\
{[48]}\end{array}$ & $<24$ & $\begin{array}{l}10 \mathrm{~mL} \text { vials } \\
3 \mathrm{~mL} \text { prefilled } \\
\text { pens }\end{array}$ & $\begin{array}{l}1000 \\
300\end{array}$ & 80 & 323 & 42 \\
\hline
\end{tabular}

NA not available

${ }^{a}$ Median cost in the USA calculated as the average wholesale price per 1000 units of a specified dosage

${ }^{b}$ At $200 \mathrm{U} / \mathrm{mL}$

U-500 regular insulin, which contains $500 \mathrm{U} /$ $\mathrm{mL}$ of Humulin $\mathrm{R}$ insulin, is not a true basal insulin but is targeted at patients requiring very large insulin doses. In patients with uncontrolled diabetes and insulin resistance, multiple daily injections result in significant improvements in glycemic control without increased hypoglycemia, but with significantly more weight gain and insulin doses compared with U-100 [37]. Initial prescriptions for U-500 were written in volume rather than units to avoid dose-conversion errors [38]. However, a new dispensing pen device that is dosed in units and a US Food and Drug Administration-approved syringe for use with vials do not require dose conversion [39].

\section{Premixed Insulin Formulations}

Premixed insulin formulations combine a rapidacting insulin with a longer-acting insulin. These can be prescribed for both insulin-naive patients and those already receiving insulin who require treatment intensification [3]. NPH combined with a regular insulin formulation has long been available, but newer formulations of biphasic insulin aspart or insulin lispro have emerged [6]. Premixed insulin formulations tend to result in greater $\mathrm{HbA1c}$ reductions compared with basal insulin [40]. Additionally, these have the obvious advantage of allowing two insulin formulations to be delivered in a single injection, therefore reducing the number of injections. These formulations, however, 
tend to be associated with higher rates of hypoglycemia compared with basal insulin and offer reduced dosing flexibility compared with individual treatments [41].

\section{BASAL INSULIN ANALOGS}

Basal insulin analogs have a longer duration of action than NPH, with a more stable and consistent biologic activity, resulting in more predictable blood glucose levels and a lower risk of hypoglycemia, particularly nocturnal hypoglycemia [42-44]. Compared with NPH, basal insulin analogs have reduced variability in glucose-lowering response [45]. In addition, the lower incidence of hypoglycemia may be of particular benefit to patients who fear this complication, and may facilitate titration by reducing the tendency to become overcautious when hypoglycemia occurs.

\section{First-Generation Basal Insulin Analogs}

\section{Gla-100}

Gla-100 was the first basal insulin analog to be approved for use in diabetes and is the most commonly used basal insulin analog worldwide. It has a well-established mode of action, with a less pronounced peak in its time-action profile compared with NPH insulin, an earlier onset of action at around 2-4 h, and a duration of action of around $24 \mathrm{~h}$, allowing for once-daily dosing at a time convenient for the patient. Gla-100 also has a well-established efficacy and safety profile. Compared with NPH insulin, treatment of T2D with Gla-100 results in similar or better glycemic control, but with a significant reduction in nocturnal and overall hypoglycemia with once-daily dosing [42]. Recently, a followon version of insulin glargine received regulatory approval [31]. This follow-on product showed similar safety and efficacy outcomes, either alone or combined with OADs, in insulinnaive patients and patients previously treated with insulin glargine [46, 47].

\section{IDet}

The duration of action of IDet is shorter than that of Gla-100, $<24 \mathrm{~h}$ at therapeutic doses of $\leq 0.3 \mathrm{U} / \mathrm{kg}$ in some studies [48]; because of this, some patients may benefit from divided doses twice daily rather than a single daily injection. Overall, IDet and Gla-100 have similar safety and efficacy, but higher doses of IDet were often needed in clinical trials to achieve similar glycemic effects [49]. IDet has also shown similarity to NPH in terms of glycemic control, with a lower incidence of hypoglycemia and less weight gain $[43,50]$.

\section{Second-Generation Basal Insulin Analogs}

The more recently approved Gla-300, IDeg-100, and IDeg-200 provide the advantage of oncedaily dosing and a longer duration of action [51-53].

\section{Gla-300}

Gla-300 is a formulation of insulin glargine that delivers the same number of insulin units as Gla-100, but in one-third of the injection volume. The pharmacokinetic (PK)/pharmacodynamic (PD) profiles of Gla-300 are more constant and prolonged compared with those of Gla-100, which results in continued blood-glucose control beyond $24 \mathrm{~h}$, with evenly distributed activity $[51,54]$. This allows for more flexibility in timing of dosing and reduces dayto-day variation in blood glucose values. Patients controlled on Gla-100 who switch to Gla-300 are likely to need a higher daily dose to maintain the same level of glycemic control [32]. In the EDITION 3 clinical trial involving insulin-naive patients, Gla-300 was as effective as Gla-100 at reducing $\mathrm{HbA1c}$, with a lower risk of hypoglycemia, particularly nocturnal hypoglycemia [55]. Compared with Gla-100, Gla-300 is relatively weight-neutral in patients with $\mathrm{T} 2 \mathrm{D}$, resulting in similar weight gain in patients receiving basal plus mealtime insulin, and significantly less weight gain in patients receiving OADs in addition to basal insulin [56]. The Gla300 SoloSTAR pen delivers a maximum dose of $80 \mathrm{U}$, but in a smaller injection volume. Therefore, patients who require doses $>80 \mathrm{U} /$ day 
should split the required dose into two separate injections at the same dosing time or use the SoloSTAR MAX pen, which can deliver up to $160 \mathrm{U}$ in a single injection [32].

\section{IDeg}

IDeg-100 is a modified insulin molecule with a duration of action of $>42 \mathrm{~h}$, a half-life of $>25 \mathrm{~h}$, and a flat and stable PD profile $[57,58]$. In both insulin-naive and previously insulintreated patients, IDeg-100 has demonstrated glycemic control similar to that achieved with both Gla-100 and IDet [59]. IDeg-200 is bioequivalent to IDeg-100, with a similar PD profile at steady state, suggesting interchangeability with IDeg-100 [60]. In clinical trials, both formulations showed similar glycemic control to Gla-100 in insulin-naive patients, with a lower incidence of nocturnal hypoglycemia, particularly for IDeg-200 [53, 61-64]. In patients with T2D and at least one hypoglycemia risk factor, patients switching to IDeg from Gla-100 experienced reduced rates of overall symptomatic hypoglycemia compared with those switching to Gla-100 from IDeg [65]. IDeg-200 may reduce injection volumes and improve dosing flexibility compared with first-generation basal insulins. In addition, the IDeg-200 pen can deliver up to $160 \mathrm{U}$, which may reduce the number of injections needed by people with high-dose insulin requirements. The different PK/PD profiles for longer-acting insulins may have implications for titration.

\section{TREATMENT ALGORITHMS}

Data from clinical studies evaluating the safety and efficacy of basal insulins in insulin-naive patients provide the basis for recommendations regarding treatment initiation and titration. Key head-to-head studies of insulin initiation vary in terms of treatment goals and schedules (Table 2). In addition to clinical trials, a number of studies have been performed to evaluate different basal insulin algorithms, with varying numbers of steps, different step sizes (i.e., magnitude of increase or decrease in insulin dose), and different titration frequencies, ranging from daily to weekly (Table 3 ). Considering the data altogether, most trials used a basal insulin starting dose of $10 \mathrm{U} /$ day, with the majority using an FPG target of approximately $100 \mathrm{mg} / \mathrm{dL}$. Most algorithms used weekly or 3-day dose adjustments and titrated insulin on the basis of a mean value from more than one and generally two to three FPG levels over the previous days. Insulin dose steps varied, with some studies using simple 2-U steps and others smaller or larger steps based on blood glucose levels. Final insulin doses varied but were often $>50 \mathrm{U} /$ day. Irrespective of the algorithm used, the initiation and titration of basal insulin was associated with pronounced improvements in HbA1c, and rates of hypoglycemia were generally low.

Overall, no particular algorithm has been consistently shown to have greater clinical benefits over the others. However, a key consideration in algorithm design is that titration must be manageable and should support healthcare professionals and patients in optimizing basal insulin therapy; simpler algorithms may therefore be preferable and also result in improved clinical outcomes. For example, a pooled analysis of patient-level data from randomized controlled clinical trials found that, although three different algorithms for initiation and titration of Gla-100 in patients with T2D resulted in similar levels of glycemic control, lower rates of hypoglycemia were seen in patients treated using simpler algorithms (standard dose increase either once a day or every 3 days if FPG was above target) compared with a more complex once-weekly, treat-to-target algorithm [74].

The use of simple titration algorithms may allow patients, under the direction and support of a healthcare provider, including their pharmacist, to adjust their own insulin dose, which could lead to fewer clinic visits and improve patients' comfort and confidence/acceptance of their insulin regimen [74]. In some studies, simple patient-driven titration algorithms for insulin initiation have been shown to be as effective as physician-driven regimens, achieving similar or better glycemic control, with generally low rates of hypoglycemia [71, 72]. However, there is evidence that, at least with 


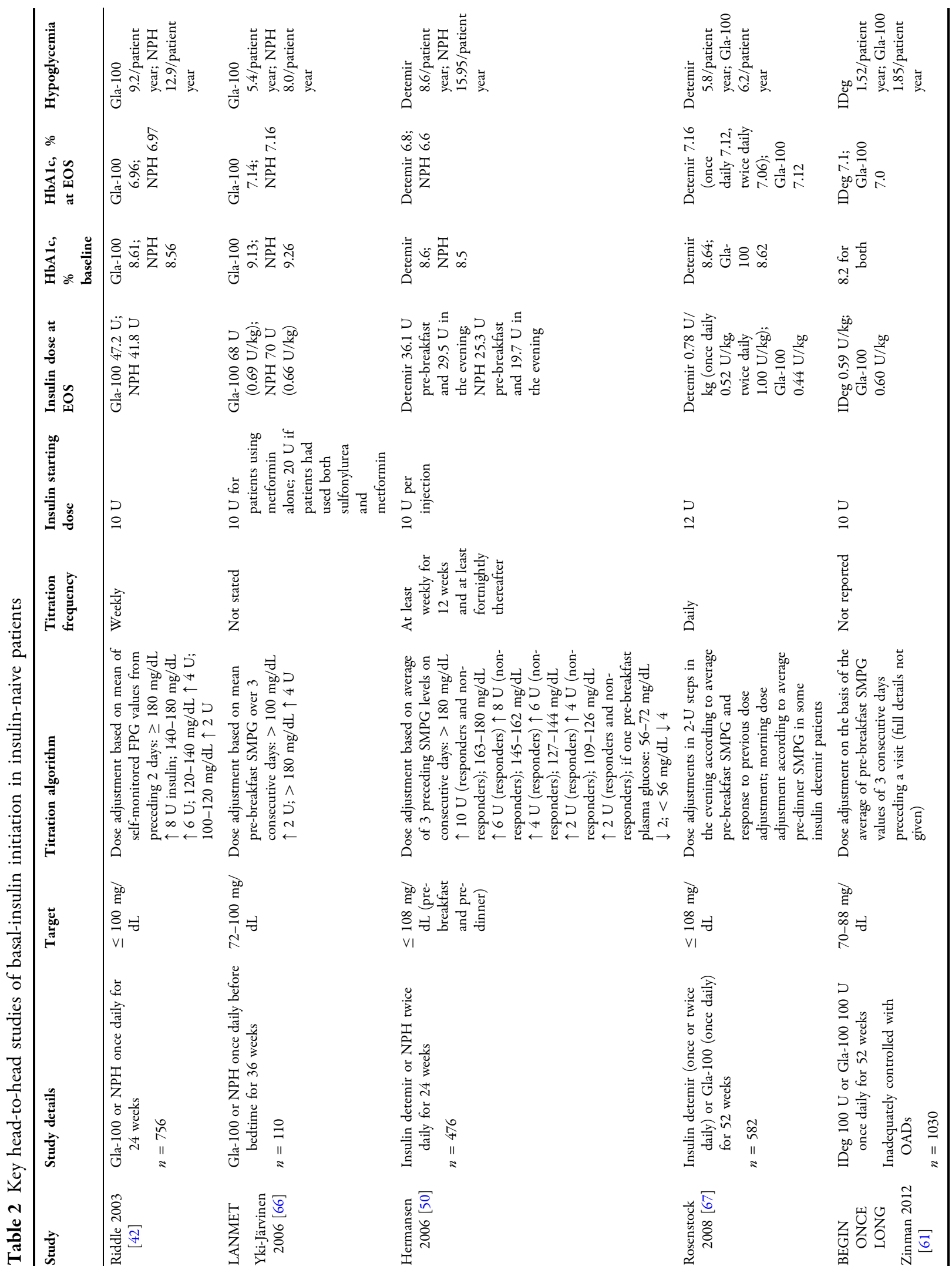




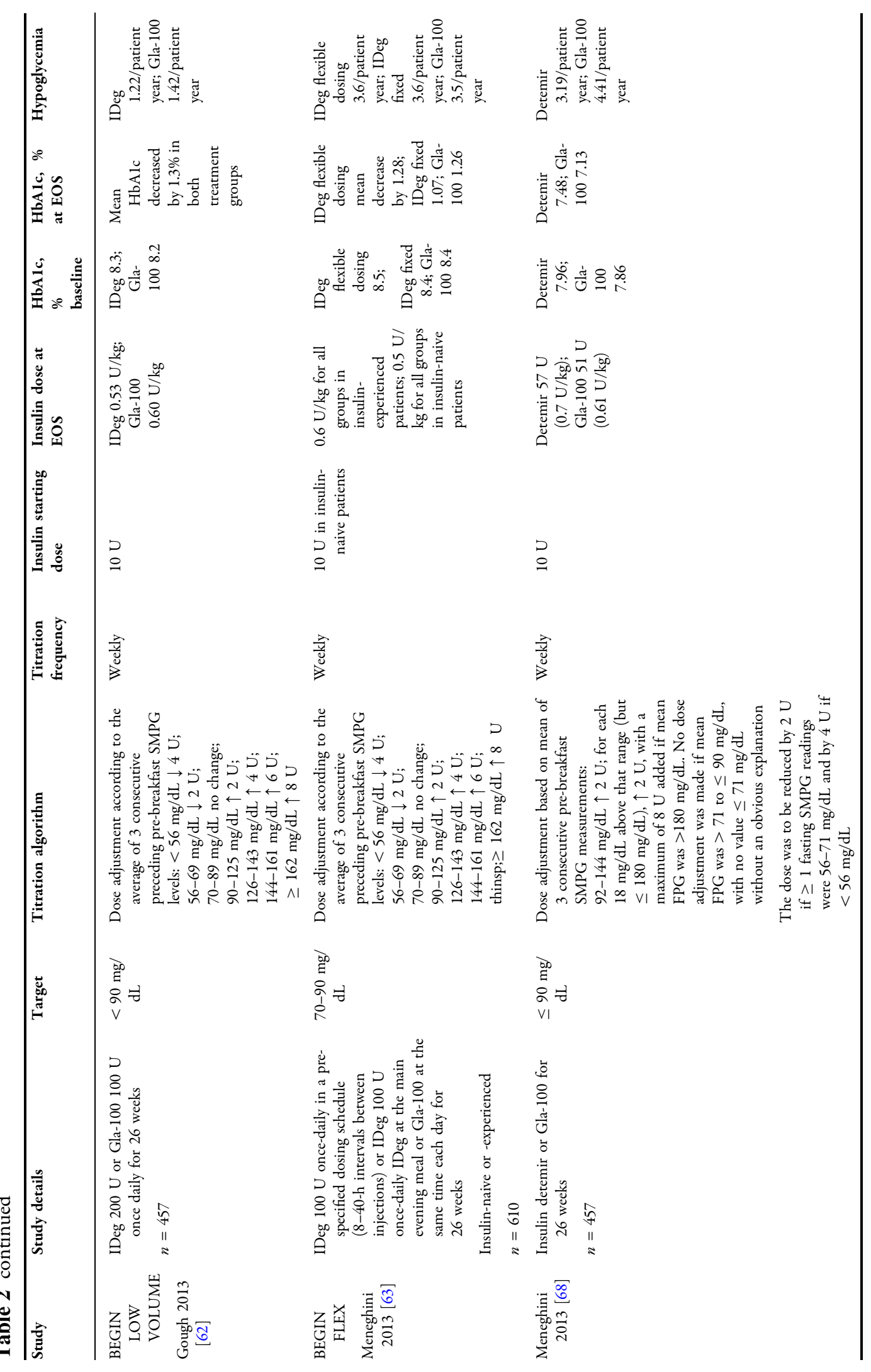




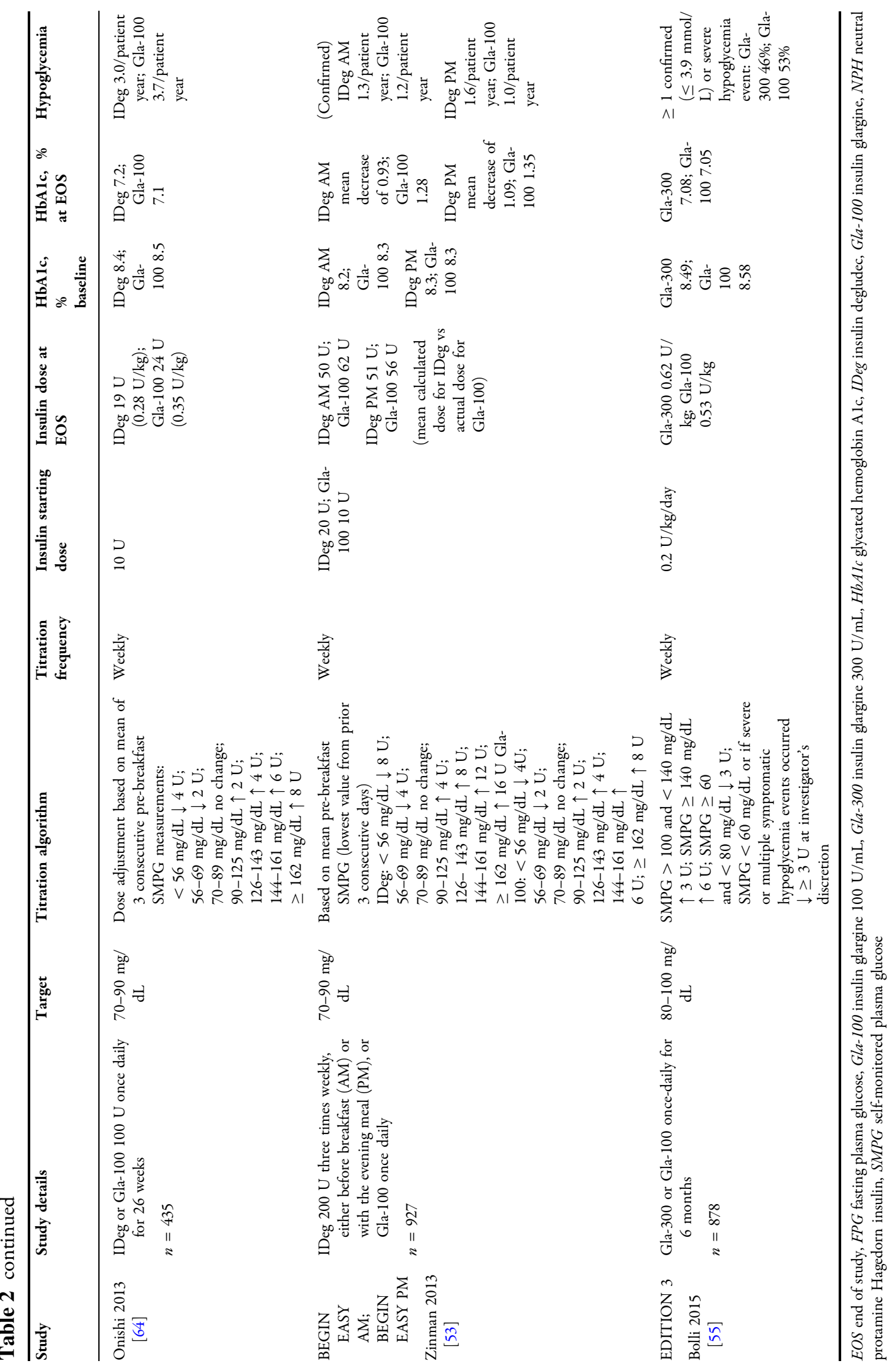




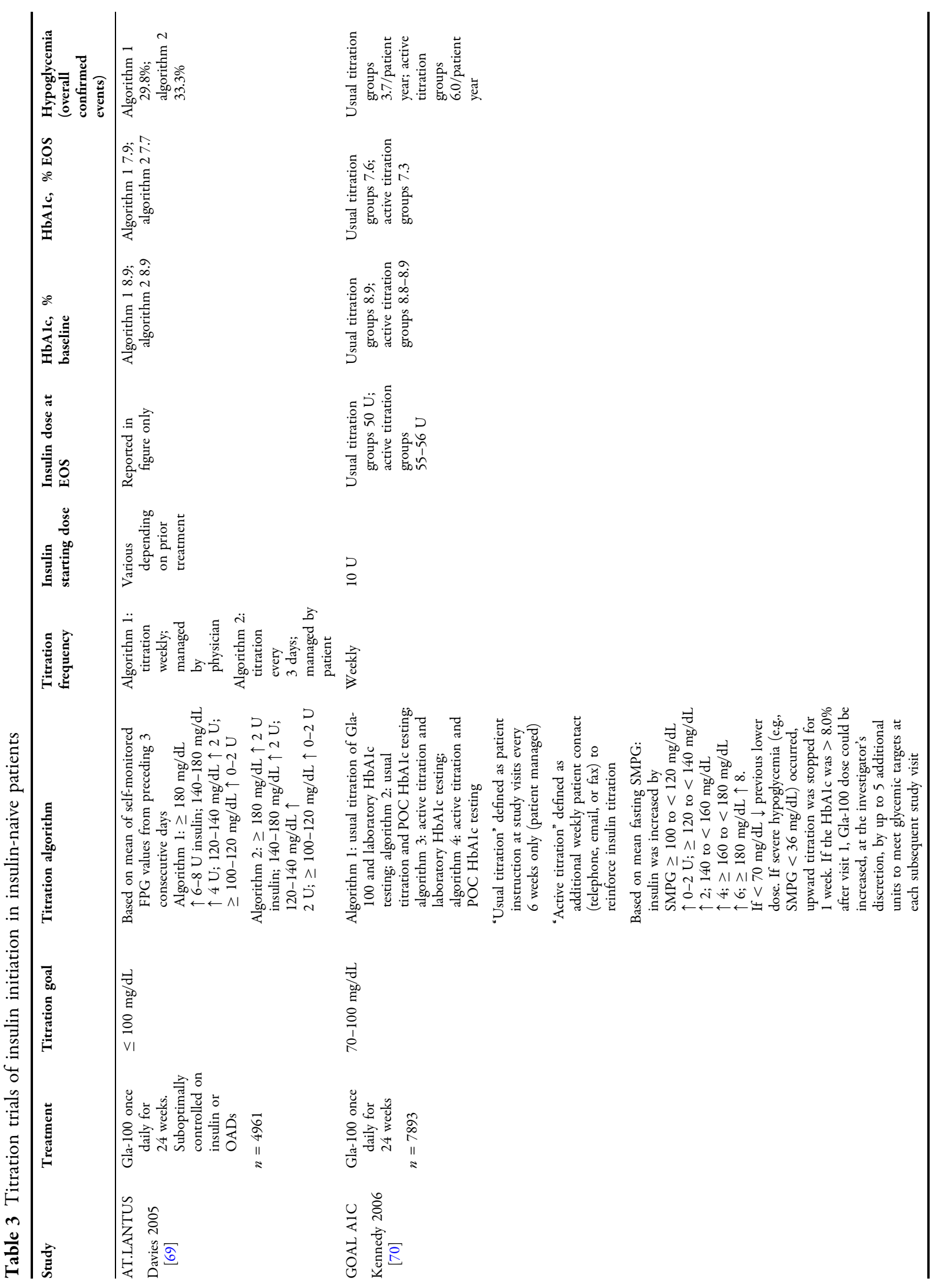




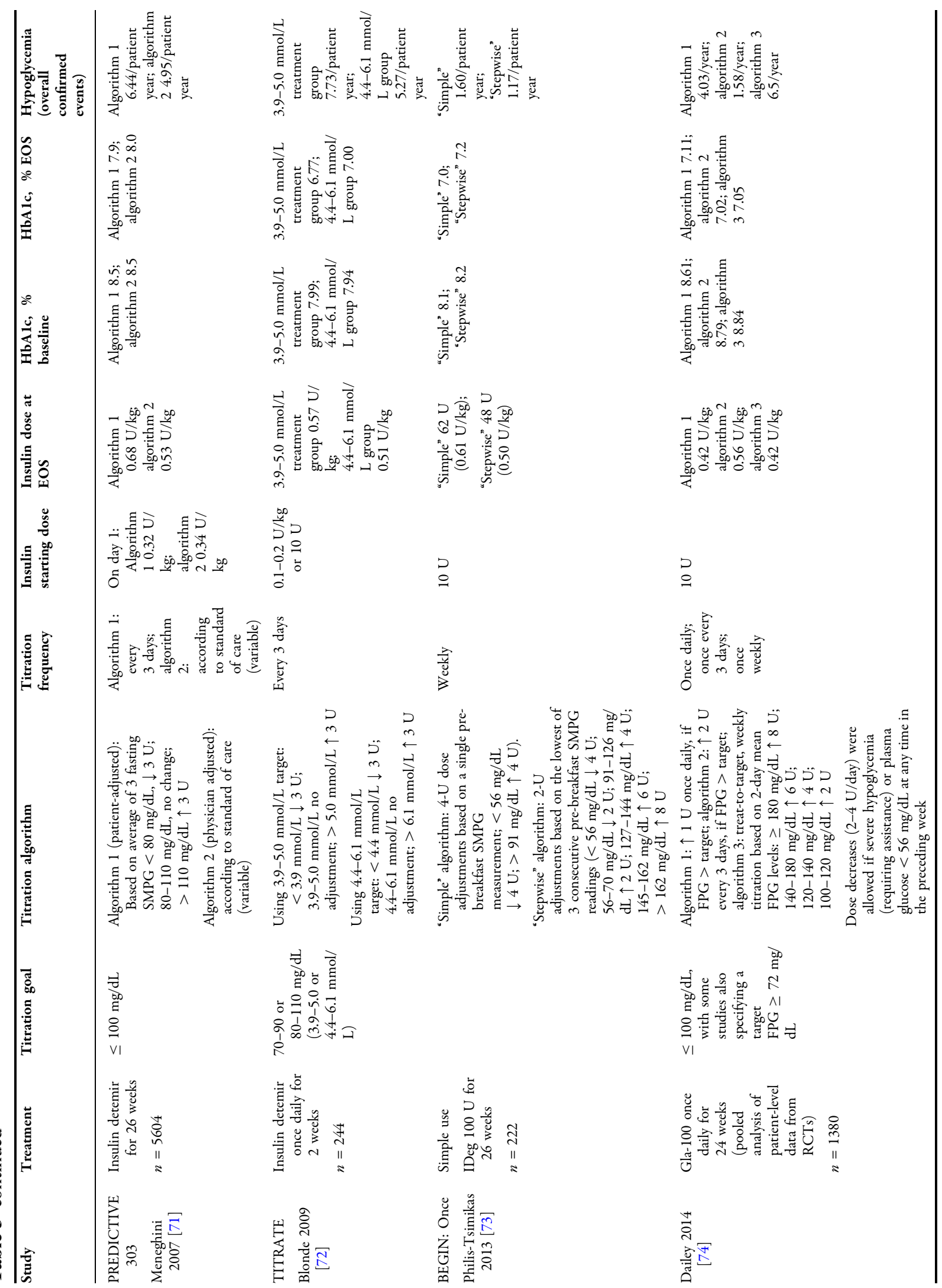




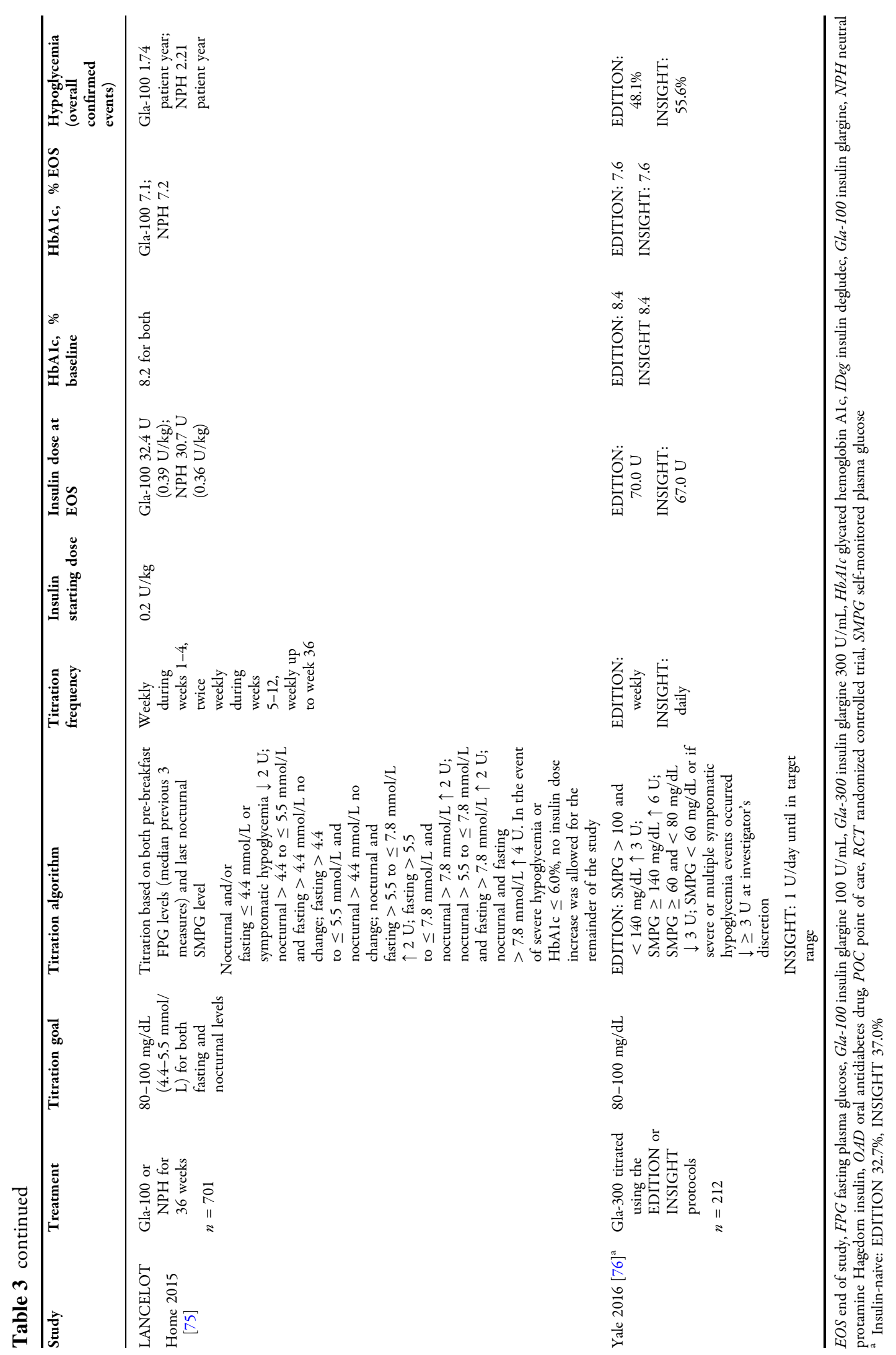


more complex titration algorithms, regular support can improve glycemic control [70].

A number of organizations have produced algorithms for the initiation, titration, and intensification of basal insulin therapy [2-6]. Although similar in many respects, they vary in terms of insulin titration schedules and targets (Table 4). When considering these recommendations, it is important to remember that what works well for one patient may not be optimal for others. Basal insulin therapy typically starts at a low dose (10 U or $0.1-0.2 \mathrm{U} / \mathrm{kg} /$ day $)$ depending on the degree of hyperglycemia [6], but patients should be made aware that this is still a safe starting point and that further titration will be needed. The simplest and most convenient strategy for basal insulin initiation is a single injection at a time chosen to best fit the patients' preferences and their overall glucose profiles [6]. While several algorithms have been used in clinical trials, the majority recommends small dose increases (e.g., $\geq 2-4 \mathrm{U}$ in patients taking higher doses) once- or twiceweekly if FPG levels are above the pre-agreed target (Table 4). This is considered a reasonable approach by several treatment guidelines $[3,5,6]$, although a more complicated "adjustable" (treat-to-target) algorithm is also recommended [5].

As with all aspects of patient care in T2D, the choice of optimal titration schedule should be personalized to the status, needs, and preferences of the patient. More frequent dose adjustments (e.g., daily) have generally not been recommended because day-to-day FPG levels vary by around 15\%, with the largest variations in patients with higher FPG values [77]. As patients approach their target FPG, smaller and less frequent dose adjustments reduce the risk of hypoglycemia [2]. During titration, the insulin dose should be reduced if any hypoglycemia occurs [6]. Reinforcement of patients' understanding of hypoglycemia (e.g., why it happens, how best to avoid it, how to manage it) and decisions as to the possible impact of hypoglycemia on the titration schedules are important aspects of successful management. Once patients achieve a stable dose of insulin, the frequency of monitoring should be reviewed [2]. In pivotal trials of basal insulins, final doses varied widely but were often $>50 \mathrm{U}$, so it is important not to abandon basal insulin titration and intensify therapy too early. However, it is equally important not to continue to increase the basal insulin dose beyond the point at which it is effective at controlling FPG.

\section{The Problem of "Over-Basalization"}

One of the major challenges faced with longerterm use of basal insulins is overuse, often referred to as "over-basalization," which occurs when basal insulin continues to be uptitrated in order to compensate for mealtime excursions when the addition of a mealtime bolus would be a better option. Because titration algorithms often do not give an upper limit for basal insulin, it may be tempting to increase the dose in an attempt to meet treatment goals. However, recent studies have shown that FPG reduction becomes proportionally smaller with increasing dose of basal insulin beyond a certain dose level, with a "ceiling effect" at around $0.5 \mathrm{U} / \mathrm{kg} /$ day, above which FPG response does not increase substantially despite increasing insulin levels [39]. FPG is particularly elevated with late and large evening meals, which leads to higher doses of basal insulin and increased hypoglycemia and weight gain; smaller portions in the evening are thus preferable during titration [78]. Pharmacists may ask patients if hypoglycemia occurs when meals are skipped or in the middle of the night, when basal insulins usually reach their peak effect, which may help avoid over-basalization.

Awareness of the diminishing returns of further increasing basal insulin and the potential benefits of introduction of other therapies at this stage are key to avoiding over-basalization. Pharmacists can aid physicians in identifying patients for whom intensification of treatment may be beneficial and by educating patients on additional medications they have been prescribed, including usage and potential side effects, which may help with patient reluctance to start a new treatment. 
Table 4 Comparison of guideline recommendations for initiation and titration of basal insulin in T2D

\begin{tabular}{|c|c|c|c|}
\hline Guideline & ADA [6] & $\mathrm{AACE} / \mathrm{ACE}[5]$ & IDF [3] \\
\hline Initial dose & $10 \mathrm{U}$ or $0.1-0.2 \mathrm{U} / \mathrm{kg} / \mathrm{day}^{\mathrm{a}}$ & $\begin{array}{l}\text { HbAlc }<8 \%: 0.1-0.2 \mathrm{U} / \mathrm{kg} / \text { day } \\
\text { HbAlc }>8 \%: 0.2-0.3 \mathrm{U} / \mathrm{kg} / \text { day }\end{array}$ & Not specified \\
\hline \multicolumn{4}{|l|}{ Titration } \\
\hline Target FPG & $\begin{array}{l}4.4-7.2 \mathrm{mmol} / \mathrm{L}(80-130 \mathrm{mg} / \mathrm{dL}) \text {, but } \\
\text { individualize to patient/disease features }\end{array}$ & $<6.1 \mathrm{mmol} / \mathrm{L}(<110 \mathrm{mg} / \mathrm{dL})$ & $\begin{array}{l}<6.5 \mathrm{mmol} / \mathrm{L} \\
\quad(<115 \mathrm{mg} / \\
\mathrm{dL})\end{array}$ \\
\hline Target HbAlc & $\begin{array}{l}\text { Usually }<7 \% \text {, but individualize to patient/ } \\
\text { disease features }{ }^{\mathrm{b}}\end{array}$ & $<7 \%$ for most patients ${ }^{\mathrm{c}}$ & Generally $<7 \%$ \\
\hline Dose change & Add $10-15 \%$ or $2-4 \mathrm{U}$ & $\begin{array}{l}\text { Fixed regimen: } 2 \mathrm{U} \\
\text { Adjustable regimen: } \\
\text { FPG }>180 \mathrm{mg} / \mathrm{dL} \text { : add } 20 \% \text { of } \\
\text { TDD } \\
\text { FPG } 140-180 \mathrm{mg} / \mathrm{dL} \text { : add } 10 \% \\
\text { of TDD } \\
\text { FPG } 110-139 \mathrm{mg} / \mathrm{dL}: \text { add } 1 \mathrm{U}\end{array}$ & Add $2 \mathrm{U}$ \\
\hline Frequency & Once- to twice-weekly & Every 2-3 days & Every 3 days \\
\hline Hypoglycemia & Reduce dose by $4 \mathrm{U}$ or $10-20 \%$ of TDD & $\begin{array}{l}\text { Reduce TDD by: } \\
\text { BG }<70 \mathrm{mg} / \mathrm{dL}: 10-20 \% \\
\text { BG }<40 \mathrm{mg} / \mathrm{dL}: 20-40 \%\end{array}$ & Not specified \\
\hline $\begin{array}{l}\text { Escalate to } \\
\text { combination } \\
\text { injectables }\end{array}$ & $\begin{array}{l}\text { Consider when FPG is } \geq 300 \mathrm{mg} / \mathrm{dL} \\
(\geq 16.7 \mathrm{mmol} / \mathrm{L}) \text { or } \mathrm{HbAlc} \geq 10 \%\end{array}$ & When targets are not achieved & Not specified \\
\hline
\end{tabular}

$A A C E / A C E$ American Association of Clinical Endocrinologists/American College of Endocrinology, $A D A$ American Diabetes Association, $B G$ blood glucose, $F P G$ fasting plasma glucose, $H b A 1 c$ glycated hemoglobin Alc, $I D F$ International Diabetes Federation, $T 2 D$ type 2 diabetes, $T D D$ total daily dose

a Depending on the degree of hyperglycemia

b Goals should be individualized on the basis of duration of diabetes, age/life expectancy, comorbid conditions, known cardiovascular disease or advanced microvascular complications, hypoglycemia unawareness, and individual patient considerations

c AACE/ACE guidelines state that HbA1c levels of $\leq 6.5 \%$ are optimal if they can be achieved in a safe and affordable manner, but patients using insulin are considered to not be achieving glycemic control and are therefore advised to intensify therapy if $\mathrm{HbAlc} \geq 7 \%$

\section{A Special Note on Initiation and Titration of the Newer Basal Insulins}

The current T2D management guidelines were drawn up before the newer longer-acting basal insulins were available. Owing to differences in their formulation and PK/PD profiles, the recommended titration algorithms may not be appropriate for these newer agents. In the BEGIN LOW VOLUME and BEGIN EASY clinical trials of IDeg-200 in insulin-naive patients, treatment was initiated at 10 or $20 \mathrm{U}$, with 
either daily or thrice-weekly dosing and onceweekly dose adjustments made according to a multistep, treat-to-target algorithm (Table 2) $[53,62]$. However, prescribing information recommends a similar regime for both IDeg-100 and IDeg-200, with a starting dose of $10 \mathrm{U}$ in insulin-naive patients, daily dosing, and dose adjustments every 3-5 days, with no recommended algorithm. Gla-300 was compared with Gla-100 in insulin-naive patients in the EDITION 3 trial [55]; the starting dose for both insulins was $0.2 \mathrm{U} / \mathrm{kg} /$ day, with weekly dose adjustments based on a simplified treat-to-target algorithm (Table 2). Gla-300 prescribing information recommends a starting dose of $0.2 \mathrm{U} / \mathrm{kg} /$ day and dose adjustments no more frequently than every 3-4 days to minimize the risk of hypoglycemia.

The optimal titration schedules for these longer-acting insulins are unknown as no comparative titration algorithm data have been published to date. However, given their longer duration of action, less aggressive titration, in which the basal insulin is titrated no more frequently than every 3 days and possibly less frequently, may be required. In addition, although both Gla-300 and IDeg-200 reduced the risk of hypoglycemia compared with Gla-100, a headto-head clinical trial of Gla-300 and IDeg in patients with T2D showed lower hypoglycemia event rates for Gla-300 in the 12-week titration period, but they are similar in the maintenance phase (BRIGHT) [79].

\section{SUMMARY}

A significant proportion of people with diabetes are failing to meet their glycemic targets, putting them at risk of increased morbidity and mortality. While there are likely to be multiple reasons for this, clinical inertia is a key issue, particularly when moving from OADs to insulin therapy and, once insulin is started, to a titrated dose that reaches the goal FPG. As with all aspects of care for people with diabetes, individualization of basal insulin initiation and titration within the context of the needs, preferences, and lifestyle of the patient is essential. Although a number of different titration algorithms have been used and compared in clinical trials, none have proven to be significantly superior to the others. Simpler dosing and titration regimens, as recommended by treatment guidelines, may be of benefit; however, these should be individualized to suit the patient and may need adjustment, depending on the basal insulin prescribed. Digital applications that provide dose-adjusting algorithms can be used together with a variety of treatment plans and dosage guidelines, based on the patient's personalized treatment plan, to support the management of adult patients with T2D treated with basal insulin. These applications can be designed to share the data automatically with the patient's healthcare team, implying that there are multiple points of care at which providers can work with the patient toward his or her goal [80]. Even with the availability of such technology, pharmacists are still in a unique position to provide support to patients during insulin titration, when clinical inertia is an issue, and when other issues such as "over-basalization" and poor treatment adherence are suspected. As a regular point of contact for the patient and other healthcare providers, the pharmacist is well positioned to identify areas of unmet need for the individual patient, in particular for those taking mixed regimens or rapid-acting insulins who experience frequent hypoglycemia episodes or glucose excursions, and/or those with a lower education level or living in rural areas with fewer resources. With the increasing footprint of digital technologies in day-to-day healthcare, the pharmacy may become a centralized hub through which the interpersonal relationship between the pharmacist and the patient in collaboration with the primary or specialist healthcare provider affords a bridge to the patient's data and contributes to improved diabetes care.

\section{ACKNOWLEDGEMENTS}

Funding. This review, article processing charges and the open access fee were covered by Sanofi US, Inc. All authors had full access to the 
information used to compile this work and take complete responsibility for the integrity and accuracy of this review.

Medical Writing and Editorial Assistance. The authors received writing/editorial support in the preparation of this manuscript provided by Rasilaben Vaghjiani, PhD, of Excerpta Medica, funded by Sanofi US, Inc.

Authorship. All named authors meet the International Committee of Medical Journal Editors criteria for authorship for this article, take responsibility for the integrity of the work as a whole, and have given their approval for this version to be published.

Authorship Contributions. All authors contributed to the concept/design and writing of this manuscript, including critical review, editing of each draft, and approval of the submitted version.

Disclosures. Dhiren Patel is on the speakers' bureau of AstraZeneca, Boehringer Ingelheim, Mannkind Corporation, Merck \& Co., Novo Nordisk, and Sanofi and is an advisory board member/consultant for Eli Lilly and Company, Merck \& Co., Novo Nordisk, and Sanofi. Curtis Triplitt is on the speakers' bureau of AstraZeneca, Boehringer Ingelheim, and Novo Nordisk and is an advisory board member for Novo Nordisk and Sanofi. Jennifer Trujillo is an advisory board member for Sanofi.

Compliance with Ethics Guidelines. This article is based on previously conducted studies and does not contain any studies with human participants or animals performed by any of the authors.

Data Availability. Data sharing is not applicable to this article as no datasets were generated or analyzed during the current study.

Open Access. This article is distributed under the terms of the Creative Commons Attribution-NonCommercial 4.0 International License (http://creativecommons.org/licenses/ by-nc/4.0/), which permits any noncommercial use, distribution, and reproduction in any medium, provided you give appropriate credit to the original author(s) and the source, provide a link to the Creative Commons license, and indicate if changes were made.

\section{REFERENCES}

1. World Health Organization. Global report on diabetes. 2016. http://apps.who.int/iris/bitstream/ 10665/204871/1/9789241565257_eng.pdf?ua=1. Accessed 23 July 2018.

2. Inzucchi SE, Bergenstal RM, Buse JB, et al. Management of hyperglycaemia in type 2 diabetes: a patient-centered approach. Position statement of the American Diabetes Association (ADA) and the European Association for the Study of Diabetes (EASD). Diabetologia. 2012;55:1577-96.

3. International Diabetes Federation Guideline Development Group. Global guideline for type 2 diabetes. Diabetes Res Clin Pract. 2014;104:1-52.

4. Davies MJ, D'Alessio DA, Fradkin J, et al. Management of hyperglycaemia in type 2 diabetes, 2018. A consensus report by the American Diabetes Association (ADA) and the European Association for the Study of Diabetes (EASD). Diabetologia. 2018;61:2461-98.

5. Garber AJ, Abrahamson MJ, Barzilay JI, et al. Consensus statement by the American Association of Clinical Endocrinologists and American College of Endocrinology on the comprehensive type 2 diabetes management algorithm-2018 executive summary. Endoc Practice. 2018;24:91-120.

6. American Diabetes Association. Standards of medical care in diabetes-2018. Diabetes Care. 2018;41(Suppl 1):S1-159.

7. Stark Casagrande S, Fradkin JE, Saydah SH, Rust KF, Cowie CC. The prevalence of meeting A1C, blood pressure, and LDL goals among people with diabetes, 1988-2010. Diabetes Care. 2013;36:2271-9.

8. Strain WD, Blüher M, Paldánius P. Clinical inertia in individualising care for diabetes: is there time to do more in type 2 diabetes? Diabetes Ther. 2014;5:347-54.

9. Khunti K, Wolden ML, Thorsted BL, Andersen M, Davies MJ. Clinical inertia in people with type 2 diabetes: a retrospective cohort study of more than 80,000 people. Diabetes Care. 2013;36:3411-7. 
10. Khunti K, Nikolajsen A, Thorsted BL, Andersen M, Davies MJ, Paul SK. Clinical inertia with regard to intensifying therapy in people with type 2 diabetes treated with basal insulin. Diabetes Obes Metab. 2016;18:401-9.

11. Peyrot M, Barnett AH, Meneghini LF, SchummDraeger PM. Insulin adherence behaviours and barriers in the multinational Global Attitudes of Patients and Physicians in Insulin Therapy study. Diabet Med. 2012;29:682-9.

12. Peyrot M, Rubin RR, Lauritzen T, et al. Resistance to insulin therapy among patients and providers: results of the cross-national Diabetes Attitudes, Wishes, and Needs (DAWN) study. Diabetes Care. 2005;28:2673-9.

13. Ide L. Expanding pharmacist provider status can improve diabetes management. 2015. https://www. ajmc.com/contributor/lucienne-ide-md-phd/2015/ 12/expanding-pharmacist-provider-status-can-impro ve-diabetes-management. Accessed 23 July 2018.

14. Shane-McWhorter L. The scope and standards for the practice of diabetes education by pharmacists. American Association of Diabetes Educators. https:// www.diabeteseducator.org/docs/default-source/legacydocs/_resources/pdf/PharmDScopeStandards.pdf. Accessed 23 July 2018.

15. Weeks G, George J, Maclure K, Stewart D. Nonmedical prescribing versus medical prescribing for acute and chronic disease management in primary and secondary care. Cochrane Datab Syst Rev. 2016;11:CD011227.

16. Collins C, Limone BL, Scholle JM, Coleman CI. Effect of pharmacist intervention on glycemic control in diabetes. Diabet Res Clin Pract. 2011;92:145-52.

17. McCord AD. Clinical impact of a pharmacist-managed diabetes mellitus drug therapy management service. Pharmacotherapy. 2006;26:248-53.

18. Morello CM, Zadvorny EB, Cording MA, Suemoto RT, Skog J, Harari A. Development and clinical outcomes of pharmacist-managed diabetes care clinics. Am J Health Syst Pharm. 2006;63:1325-31.

19. Mehuys E, Van Bortel L, De Bolle L, et al. Effectiveness of a community pharmacist intervention in diabetes care: a randomized controlled trial. J Clin Pharm Ther. 2011;36:602-13.

20. Ourth H, Groppi J, Morreale AP, Quicci-Roberts K. Clinical pharmacist prescribing activities in the Veterans Health Administration. Am J Health Syst Pharm. 2016;73:1406-15.
21. Sullivan J, Jett BP, Cradick M, Zuber J. Effect of clinical pharmacist intervention on A1C reduction in veteran patients with type 2 diabetes in a rural setting. Ann Pharmacother. 2016;50:1023-7.

22. Maxwell LG, McFarland MS, Baker JW, Cassidy RF. Evaluation of the impact of a pharmacist-led telehealth clinic on diabetes-related goals of therapy in a veteran population. Pharmacotherapy. 2016;36:348-56.

23. Deters MA, Laven A, Castejon A, et al. Effective interventions for diabetes patients by community pharmacists: a meta-analysis of pharmaceutical care components. Ann Pharmcother. 2018;52:198-211.

24. Salvo MC, Brooks AM. Glycemic control and preventive care measures of indigent diabetes patients within a pharmacist-managed insulin titration program vs standard care. Ann Pharmacother. 2012;46:29-34.

25. Rochester CD, Leon N, Dombrowski R, Haines ST. Collaborative drug therapy management for initiating and adjusting insulin therapy in patients with type 2 diabetes mellitus. Am J Health Syst Pharm. 2010;67:42-8.

26. Al Hamarneh YN, Charrois T, Lewanczuk R, Tsuyuki RT. Pharmacist intervention for glycaemic control in the community (the RxING study). BMJ Open. 2013;3:e003154.

27. Pitlick JM, Brooks AD. Glycemic control in pharmacist-managed insulin titration versus standard care in an indigent population. Diabetes Spectrum. 2011;24:211-7.

28. Weidman-Evans E, Evans J, Eastwood R, Fort A. Implementation of a pharmacist-run telephonic insulin titration service. J Am Pharm Assoc. 2003;2012(52):e266-72.

29. American Pharmacists Association. Understanding insulin management: role of the pharmacist. Pharmacy Today. 2014;20:85-96.

30. Lantus. US prescribing information (PI). http:// www.accessdata.fda.gov/drugsatfda_docs/label/ 2009/021081s034lbl.pdf. Accessed 23 July 2018.

31. Basaglar. US prescribing information (PI). http:// uspl.lilly.com/basaglar/basaglar.html\#pi. Accessed 4 Mar 2019.

32. Toujeo. US prescribing information (PI). http:// products.sanofi.us/toujeo/toujeo.pdf. Accessed 30 Aug 2018.

33. Tresiba. US prescribing information (PI). https:// www.novo-pi.com/tresiba.pdf. Accessed 4 Mar 2019. 
34. Levemir. US prescribing information (PI). http:// www.accessdata.fda.gov/drugsatfda_docs/label/2012/ 021536s037lbl.pdf. Accessed 23 July 2018.

35. Heise T, Pieber TR. Towards peakless, reproducible and long-acting insulins. An assessment of the basal analogues based on isoglycaemic clamp studies. Diabetes Obes Metab. 2007;9:648-59.

36. Jehle PM, Micheler C, Jehle DR, Breitig D, Boehm BO. Inadequate suspension of neutral protamine Hagendorn (NPH) insulin in pens. Lancet. 1999;354:1604-7.

37. Reutrakul S, Wroblewski K, Brown RL. Clinical use of U-500 regular insulin: review and meta-analysis. J Diabetes Sci Technol. 2012;6:412-20.

38. Meneghini L. New insulin preparations: a primer for the clinician. Cleve Clin J Med. 2016;83(5 Suppl 1):S27-33.

39. Reid T, Reid T, Gao L, et al. How much is too much? Outcomes in patients using high-dose insulin glargine. Int J Clin Pract. 2016;70:56-65.

40. Rys P, Wojciechowski P, Siejka S, Małecki P, Hak $Ł$, Malecki MT. A comparison of biphasic insulin aspart and insulin glargine administered with oral antidiabetic drugs in type 2 diabetes mellitus-a systematic review and meta-analysis. Int J Clin Pract. 2014;68:304-13.

41. Aschner P, Sethi B, Gomez-Peralta F, et al. Insulin glargine compared with premixed insulin for management of insulin-naïve type 2 diabetes patients uncontrolled on oral antidiabetic drugs: the openlabel, randomized GALAPAGOS study. J Diabetes Complications. 2015;29:838-45.

42. Riddle MC, Rosenstock J, Gerich J. The treat-totarget trial: randomized addition of glargine or human NPH insulin to oral therapy of type 2 diabetic patients. Diabetes Care. 2003;26:3080-6.

43. Philis-Tsimikas A, Charpentier G, Clauson P, Ravn GM, Roberts VL, Thorsteinsson B. Comparison of once-daily insulin detemir with NPH insulin added to a regimen of oral antidiabetic drugs in poorly controlled type 2 diabetes. Clin Ther. 2006;28:1569-81.

44. Heise T, Nosek L, Rønn BB, et al. Lower withinsubject variability of insulin detemir in comparison to NPH insulin and insulin glargine in people with type 1 diabetes. Diabetes. 2004;53:1614-20.

45. Hartman I. Insulin analogs: impact on treatment success, satisfaction, quality of life, and adherence. Clin Med Res. 2008;6:54-67.
46. Rosenstock J, Hollander P, Bhargava A, et al. Similar efficacy and safety of LY2963016 insulin glargine and insulin glargine (Lantus) in patients with type 2 diabetes who were insulin-naïve or previously treated with insulin glargine: a randomized, double-blind controlled trial (the ELEMENT 2 study). Diabetes Obes Metab. 2015;17:734-41.

47. Hadjiyianni I, Dahl D, Lacaya LB, Pollom RK, Chang CL, Ilag LL. Efficacy and safety of LY2963016 insulin glargine in patients with type 1 and type 2 diabetes previously treated with insulin glargine. Diabetes Obes Metab. 2016;18:425-9.

48. Plank J, Bodenlenz M, Sinner F, et al. A doubleblind, randomized, dose-response study investigating the pharmacodynamic and pharmacokinetic properties of the long-acting insulin analog detemir. Diabetes Care. 2005;28:1107-12.

49. Swinnen SG, Simon AC, Holleman F, Hoekstra JB, Devries JH. Insulin detemir versus insulin glargine for type 2 diabetes mellitus. Cochrane Database Syst Rev. 2011;7:CD006383.

50. Hermansen K, Davies M, Derezinski T, Martinez Ravn G, Clauson P, Home P. A 26-week, randomized, parallel, treat-to-target trial comparing insulin detemir with NPH insulin as add-on therapy to oral glucose-lowering drugs in insulin-naive people with type 2 diabetes. Diabetes Care. 2006;29:1269-74.

51. Becker RH, Dahmen R, Bergmann K, Lehmann A, Jax T, Heise T. New insulin glargine 300 units $\mathrm{mL}^{-1}$ provides a more even activity profile and prolonged glycemic control at steady state compared with insulin glargine 100 units $\mathrm{mL}^{-1}$. Diabetes Care. 2015;38:637-43.

52. Heller S, Mathieu C, Kapur R, Wolden ML, Zinman B. A meta-analysis of rate ratios for nocturnal confirmed hypoglycaemia with insulin degludec vs. insulin glargine using different definitions for hypoglycaemia. Diabet Med. 2016;33:478-87.

53. Zinman B, DeVries JH, Bode B, et al. Efficacy and safety of insulin degludec three times a week versus insulin glargine once a day in insulin-naive patients with type 2 diabetes: results of two phase 3, 26 weeks, randomised, open-label, treat-to-target, non-inferiority trials. Lancet Diabetes Endocrinol. 2013;1:123-31.

54. Bailey TS, Pettus B, Roussel R, et al. Morning administration of $0.4 \mathrm{U} / \mathrm{kg} / \mathrm{day}$ insulin glargine $300 \mathrm{U} / \mathrm{mL}$ provides less fluctuating 24-h pharmacodynamics and more even pharmacokinetic profiles compared with insulin degludec $100 \mathrm{U} / \mathrm{mL}$ in type 1 diabetes. Diabetes Metab. 2018;44:15-21.

55. Bolli GB, Riddle MC, Bergenstal RM, et al. New insulin glargine $300 \mathrm{U} / \mathrm{ml}$ compared with glargine 
$100 \mathrm{U} / \mathrm{ml}$ in insulin-naïve people with type 2 diabetes on oral glucose-lowering drugs: a randomized controlled trial (EDITION 3). Diabetes Obes Metab. 2015;17:386-94.

56. Ritzel R, Roussel R, Bolli GB, et al. Patient-level meta-analysis of the EDITION 1, 2 and 3 studies: glycaemic control and hypoglycaemia with new insulin glargine $300 \mathrm{U} / \mathrm{ml}$ versus glargine $100 \mathrm{U} / \mathrm{ml}$ in people with type 2 diabetes. Diabetes Obes Metab. 2015;17:859-67.

57. Heise T, Nosek L, Bøttcher SG, Hastrup H, Haahr H. Ultra-long-acting insulin degludec has a flat and stable glucose-lowering effect in type 2 diabetes. Diabetes Obes Metab. 2012;14:944-50.

58. Haahr H, Heise T. A review of the pharmacological properties of insulin degludec and their clinical relevance. Clin Pharmacokinet. 2014;53:787-800.

59. Thuillier P, Alavi Z, Kerlan V. Long-term safety and efficacy of insulin degludec in the management of type 2 diabetes. Diabetes Metab Syndr Obes. 2015;8:483-93.

60. Korsatko S, Deller S, Koehler G, et al. A comparison of the steady-state pharmacokinetic and pharmacodynamic profiles of 100 and $200 \mathrm{U} / \mathrm{mL}$ formulations of ultra-long-acting insulin degludec. Clin Drug Investig. 2013;33:515-21.

61. Zinman B, Philis-Tsimikas A, Cariou B, et al. Insulin degludec versus insulin glargine in insulin-naive patients with type 2 diabetes: a 1-year, randomized, treat-to-target trial (BEGIN Once Long). Diabetes Care. 2012;35:2464-71.

62. Gough SC, Bhargava A, Jain R, Mersebach H, Rasmussen S, Bergenstal RM. Low-volume insulin degludec 200 units/ml once daily improves glycemic control similarly to insulin glargine with a low risk of hypoglycemia in insulin-naïve patients with type 2 diabetes: a 26-week, randomized, controlled, multinational, treat-to-target trial: the BEGIN LOW VOLUME trial. Diabetes Care. 2013;36:2536-42.

63. Meneghini L, Atkin SL, Gough SC, et al. The efficacy and safety of insulin degludec given in variable once-daily dosing intervals compared with insulin glargine and insulin degludec dosed at the same time daily: a 26-week, randomized, open-label, parallel-group, treat-to-target trial in individuals with type 2 diabetes. Diabetes Care. 2013;36:858-64.

64. Onishi Y, Iwamoto Y, Yoo SJ, Clauson P, Tamer SC, Park S. Insulin degludec compared with insulin glargine in insulin-naïve patients with type 2 diabetes: a 26-week, randomized, controlled, Pan-
Asian, treat-to-target trial. J Diabetes Investig. 2013;4:605-12.

65. Wysham C, Bhargava A, Chaykin L, et al. Effect of insulin degludec vs insulin glargine U100 on hypoglycemia in patients with type 2 diabetes: the SWITCH 2 randomized clinical trial. JAMA. 2017;318:45-56.

66. Yki-Järvinen H, Kauppinen-Mäkelin R, Tiikkainen $\mathrm{M}$, et al. Insulin glargine or NPH combined with metformin in type 2 diabetes: the LANMET study. Diabetologia. 2006;49:442-51.

67. Rosenstock J, Davies M, Home PD, Larsen J, Koenen C, Schernthaner G. A randomised, 52-week, treatto-target trial comparing insulin detemir with insulin glargine when administered as add-on to glucose-lowering drugs in insulin-naïve people with type 2 diabetes. Diabetologia. 2008;51:408-16.

68. Meneghini L, Kesavadev J, Demissie M, Nazeri A, Hollander P. Once-daily initiation of basal insulin as add-on to metformin: a 26-week, randomized, treat-to-target trial comparing insulin detemir with insulin glargine in patients with type 2 diabetes. Diabetes Obes Metab. 2013;15:729-36.

69. Davies M, Storms F, Shutler S, Bianchi-Biscay M, Gomis R. Improvement of glycemic control in subjects with poorly controlled type 2 diabetes: comparison of two treatment algorithms using insulin glargine. Diabetes Care. 2005;28:1282-8.

70. Kennedy L, Herman WH, Strange P, Harris A. Impact of active versus usual algorithmic titration of basal insulin and point-of-care versus laboratory measurement of HbA1c on glycemic control in patients with type 2 diabetes: the Glycemic Optimization with Algorithms and Labs at Point of Care (GOAL A1C) trial. Diabetes Care. 2006;29:1-8.

71. Meneghini L, Koenen C, Weng W, Selam JL. The usage of a simplified self-titration dosing guideline (303 Algorithm) for insulin detemir in patients with type 2 diabetes-results of the randomized, controlled PREDICTIVE ${ }^{\mathrm{TM}} 303$ study. Diabetes Obes Metab. 2007;9:902-13.

72. Blonde L, Merilainen M, Karwe V, Raskin P. Patientdirected titration for achieving glycaemic goals using a once-daily basal insulin analogue: an assessment of two different fasting plasma glucose targets-the TITRATE study. Diabetes Obes Metab. 2009;11:623-31.

73. Philis-Tsimikas A, Brod M, Niemeyer M, Ocampo Francisco AM, Rothman J. Insulin degludec oncedaily in type 2 diabetes: simple or step-wise titration (BEGIN: once simple use). Adv Ther. 2013;30:607-22. 
74. Dailey G, Aurand L, Stewart J, Ameer B, Zhou R. Comparison of three algorithms for initiation and titration of insulin glargine in insulin-naive patients with type 2 diabetes mellitus. J Diabetes. 2014;6:176-83.

75. Home PD, Bolli GB, Mathieu C, et al. Modulation of insulin dose titration using a hypoglycaemia-sensitive algorithm: insulin glargine versus neutral protamine Hagedorn insulin in insulin-naïve people with type 2 diabetes. Diabetes Obes Metab. 2015;17:15-22.

76. Yale J-F, Harris SB, Berard L, Groleau M, JavadiP, Stewart J. Safety and efficacy of a pragmatic selftitration 1 unit/day (INSIGHT) algorithm for insulin glargine $300 \mathrm{U} / \mathrm{mL}$ (Gla-300). Poster presented at the 52nd European Association for the Study of Diabetes (EASD) annual meeting; September 12-16, 2016; Munich, Germany. https://www.easd.org/ virtualmeeting/home.html\#!resources/safety-andefficacy-of-a-pragmatic-self-titration-1-unit-dayinsight-algorithm-for-insulin-glargine-300-u-ml- gla-300-d617e461-efcf-4b97-b66f-f0d3171bb987. Accessed 23 July 2018.

77. Ollerton RL, Playle R, Ahmed K, Dunstan FD, Luzio SD, Owens DR. Day-to-day variability of fasting plasma glucose in newly diagnosed type 2 diabetic subjects. Diabetes Care. 1999;22:394-8.

78. King AB. Misled by the morning "fasting" plasma glucose. J Diabetes Sci Technol. 2015;9:1342-5.

79. Rosenstock J, Cheng A, Ritzel R, et al. More similarities than differences testing insulin glargine 300 units/mL versus insulin degludec units/mL in insulin-naive type 2 diabetes: the Randomized Head-to-Head BRIGHT Trial. Diabetes Care. 2018;4:2147-54.

80. FDA. Department of Health and Human Services Section review of $510(\mathrm{k})$. 2016. https://www. accessdata.fda.gov/cdrh_docs/pdf16/K161433.pdf. Accessed 23 July 2018. 